\title{
EATING DISORDERS RISK GROUPS IN THE CZECH REPUBLIC - CROSS-SECTIONAL EPIDEMIOLOGIC PILOT STUDY
}

\author{
Vladimír Janout, Gabriela Janoutová
}

Department of Preventive Medicine, Faculty of Medicine, Palacký University, Hněvotínská 3, 77515 Olomouc, Czech Republic

Received: October 10, 2004

Key words: Eating disorders/Epidemiologic study/Risk factors

Objective: determination of risk groups for eating disorders in the population of young girls, primarily affiliated to certain sports or professional categories.

Method: standardized Eating Attitude Test (EAT) questionnaire (40 questions) and general attitude questionnaire (43 other questions specific to eating disorders) were used.

Results: out of the total 403 persons questioned $11.7 \%$ had a score from EAT questionnaire $>29$ points. These persons represent a potential risk population for the eventual development of eating disorder. Out of the total 403 persons $10.9 \%$ had the Body Mass Index (BMI) lower or equal to 17.5. Out of these, only 5 individuals had the score $>29$ because, especially at potential or initial stages, these two parameters do not have to necessarily correspond. Top gymnasts and figure skaters, followed by the models, dancers, ballet dancers and the cosmetic school students can be classified as having the highest degree of risk.

Discussion: assessment of the frequency of the condition which already shows signs of the beginning of a food intake disorder is important prerequisite for primary and secondary prevention of this disorder.

\section{INTRODUCTION}

Epidemiological studies suggest anorexia and bulimia nervosa are prevalent among teenage girls and young women unable to adjust to the new life style of modern society ${ }^{1}$. Because their idea of success is associated with slimness these individuals try to stand out by being even slimmer than others. The seriousness of these disorders is underscored by the fact that they have a negative impact on basic human necessities, including the drive to live. Anorexia and bulimia nervosa were recently recognized by the World Health Organization as major medical conditions requiring medical attention.

Because the incidence of anorexia and bulimia nervosa is almost everywhere rising ${ }^{2}$, it is important to identify those most at risk in the overall population and the major risk factors involved. The present study focuses on sex, age, and social or professional status in an attempt to increase our understanding of the problem.

\section{OBJECTIVE OF THE STUDY}

Current estimates place the incidence of mental anorexia at $0.5 \%-1.0 \%$ and bulimia at $1.0 \%-3.0 \%$. However, both conditions are significantly underdiagnosed and the potential for developing such diseases is much higher than currently thought. The objective of this study was to determine the risk groups in students attending secondary schools and universities, and in girls performing special activities.

\section{METHODS}

\section{Group characteristics}

This pilot study was performed in the eight population groups (Table 1). 403 respondents from the eight groups above were examined. A group of fifth-year Faculty of Medicine students was selected for comparison with other groups, representing older girls with a lower risk. The majority of girls ( $83.8 \%$ ) were 15 to 19 years of age (range: 13 to 26 years), an age at which they are most vulnerable to the disorder. Approximately about one third had completed secondary school. Half the respondents resided in a large city and the other half in the suburbs or in the country. Most girls were single (97\%).

Cases of this illness requiring hospitalization at the Psychiatric clinic of the Faculty of Medicine, Palacky University, Olomouc (1993-1994) were used for comparison. All patients completed a questionnaire requesting data relevant to the condition before hospitalization (i. e., prior to medical treatment).

\section{Examination procedures}

Each study patient completed an anonymous questionnaire consisting of two parts: 
- Part 1 was a standardized EAT (Eating Attitude Test) questionnaire received from the Faculty of Medicine, Charles University, Prague. This questionnaire contained 40 questions related to eating habits, which were graded as follows: always, very often, often, sometimes, rarely, never.

The points for each question were added up and evaluated as follows:

- $\leq 29$ points - normal (the less the better)

- $>29$ points - positive

- Part 2 was a questionnaire that assessed general attitudes. This questionnaire, which contained 43 other pieces of information specific to eating disorders, was used to determine the risk for developing this disease.

The completed questionnaire, containing 90 pieces of information in total, was encoded into the epidemiological analytical program EPI INFO, which was eventually used for descriptive analysis of individual characteristics.

\section{RESULTS}

\section{Evaluation of the "EAT" questionnaire}

The "EAT" evaluation score was analyzed for each individual group. This score was evaluated from two standpoints: the frequency of persons with the score greater than 29 points, and the average score in the group examined (Table 2). The highest incidence with a score $>29$ points was observed in the top gymnast and figure skater groups, who comprised about one third of the total. A relatively high incidence was also seen in the groups of dancers, ballet dancers and models, consisting of $15 \%$ to $20 \%$ of the total. The lowest frequency was found in medical faculty students and high school students, accounting for $6.2 \%$ and $2.0 \%$ of the total, respectively.

The following problems of special interest were selected from the EAT questionnaire according to responses from each individual (data expressed as percent patients):

- Question: "I am horrified with the overweight." Response: always $(9.4 \%)$, very often $(10.4 \%)$ and often $(10.4 \%)$

- Question: "After a meal I have an urge to vomit." Response: very often $(0.2 \%)$ and often $(0.5 \%)$

- Question: "I have a feeling that the food controls my life.” Response: always ( $1.7 \%)$, very often $(3.5 \%)$ and often $(8.0 \%)$

- Question: "I am on a diet." Response: always (1.2\%), very often $(5.5 \%)$ and often $(5.2 \%)$

- Question: "I take laxatives.” Response: always (0.2\%), very often $(0.2 \%)$ and often $(1.0 \%)$

- Question: "I get my menstruation regularly." Response: never $(6.2 \%)$, rarely $(9.2 \%)$ and sometimes $(12.7 \%)$

Evaluation of the selected questions suggests that the excessive weight was a primary problem for one third of the persons questioned, and that food is a focal point of
Table 1. Number of subjects in category groups

\begin{tabular}{|l|c|}
\hline \multicolumn{1}{|c|}{ Group } & $\begin{array}{c}\text { Number } \\
\text { of subjects }\end{array}$ \\
\hline Cosmetic School students & 84 \\
High school & 49 \\
Nursery college & 142 \\
Faculty of Medicine, students & 16 \\
Fashion models & 40 \\
Dancers, including ballet dancers & 54 \\
Figure skaters & 10 \\
Top gymnasts & 8 \\
\hline
\end{tabular}

Table 2. Basic characteristics of groups

\begin{tabular}{|c|c|c|c|c|}
\hline $\begin{array}{c}\text { Group / } \\
\text { Parameter }\end{array}$ & $\begin{array}{c}\text { Score }>\mathbf{2 9} \\
\%\end{array}$ & $\begin{array}{c}\text { Average } \\
\text { score }\end{array}$ & $\begin{array}{c}\text { BMI } \\
\mathbf{1 1 7 . 5} \\
\mathbf{\%}\end{array}$ & $\begin{array}{c}\text { Average } \\
\text { BMI }\end{array}$ \\
\hline $\begin{array}{c}\text { nursery } \\
\text { college }\end{array}$ & 9.2 & 15.5 & 7.0 & 20.4 \\
\hline $\begin{array}{c}\text { cosmetic } \\
\text { school }\end{array}$ & 11.9 & 16.5 & 2.4 & 20.6 \\
\hline $\begin{array}{c}\text { high } \\
\text { school }\end{array}$ & 2.0 & 9.2 & 10.2 & 19.3 \\
\hline $\begin{array}{c}\text { medical } \\
\text { students }\end{array}$ & 6.2 & 12.0 & 0 & 20.9 \\
\hline dancers & 18.5 & 19.3 & 18.5 & 19.2 \\
\hline $\begin{array}{c}\text { fashion } \\
\text { models }\end{array}$ & 15.0 & 17.5 & $\mathbf{3 5 . 0}$ & $\mathbf{1 8 . 2}$ \\
\hline $\begin{array}{c}\text { figure } \\
\text { skaters }\end{array}$ & $\mathbf{3 0 . 0}$ & $\mathbf{2 2 . 2}$ & $\mathbf{0}$ & 19.6 \\
\hline $\begin{array}{c}\text { top } \\
\text { gymnasts }\end{array}$ & $\mathbf{3 7 . 5}$ & $\mathbf{2 2 . 0}$ & $\mathbf{3 7 . 5}$ & $\mathbf{1 8 . 0}$ \\
\hline
\end{tabular}

interest for $13 \%$ persons. The same percentage is associated with some form of diet.

The symptoms associated with food intake disorder have not yet been identified, because symptoms - such an urge to vomit after a meal or vomiting itself - were sporadically reported.

Regular or frequent use of laxatives was reported only rarely by $1.4 \%$ of subjects. Menstrual irregularities were relatively frequent - $50 \%$ of one third of persons questioned reported an interruption of menstruation for a period of more than 3 months, which is one of the diagnostic criteria for anorexia nervosa. 


\section{Proportion of subjects with BMI $<17.5(\%)$}

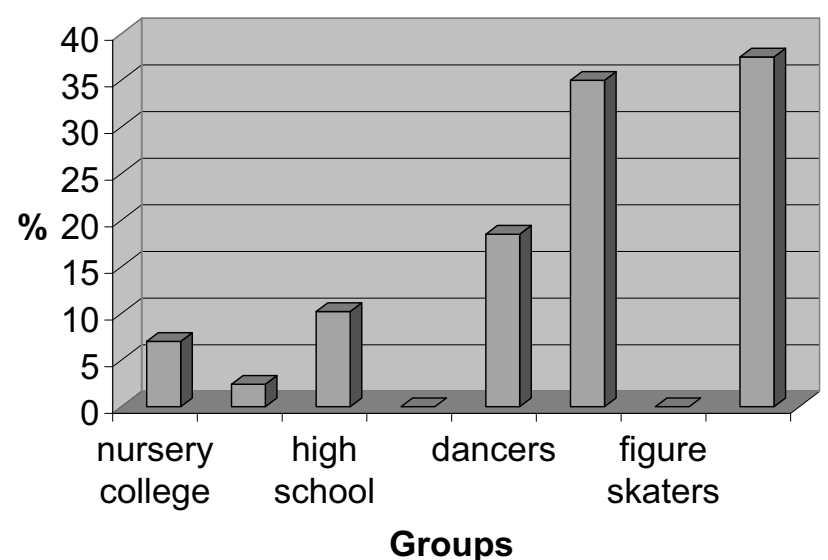

Fig. 1. Proportion of subjects with $\mathrm{BMI}<17.5$ comparison in different population groups

\section{Evaluation of the "general attitudes" questionnaire}

\section{Antropometry data evaluation}

Body weight and height was recorded for each individual according to self-reported data in the questionnaire, and the BMI was calculated. The average height was approximately the same in all groups $(167 \mathrm{~cm})$, with the exception of models where it was substantially higher $(175.6 \mathrm{~cm})$. The lowest average height was recorded in medical faculty students and top gymnasts.

The average weight was most variable in the gymnasts group. In the models group, the average weight was the fourth highest, due to their significantly greater height.

The average BMI was significantly lower for top gymnasts and models (Table 2). The highest BMI average was in the medical faculty students group.

Similarly, the percentage of persons with BMI lower than 17.5 - an important disease indicator - was highest in top gymnasts and models, reaching values of $\geq 35 \%$ (Table 2). In contrast, none of the respondents in the medical faculty students and figure skaters reached this level (Figure 1). The BMI level may be diagnostic for determining eating disorders and is one of the diagnostic guidelines.

All subjects were asked to state the ideal weight they would like to achieve. This ideal weight was then compared with the actual weight and expressed as a difference between the two. A total of 309 (76.8\%) subjects reported an ideal weight that was lower than their actual weight (range $1-18 \mathrm{~kg})$. Only 49 (12.2\%) were satisfied with their actual weight and their ideal weight was the same as their existing weight. For 26 subjects (6.5\%), their ideal weight was considered greater than their existing weight (range $1-10 \mathrm{~kg}$ ). The ideal weight for 18 subjects ( $4.5 \%)$ was not stated.

\section{Analysis of behavioural factors Food intake}

With regard to the regularity of food intake, the respondents answered the question "How many times a day do you eat?" as follows: 4 times (27\%), 5 times (24\%), 6 times (6\%) and 2 times (6\%). Therefore, on a daily basis, the majority of subjects' food intake is spread over several meals.

The respondents answered the question "How frequently are main meals skipped per day?" as follows: always $(27 \%)$, sometimes ( $58 \%)$ and eat the main course regularly (5\%). Substituting the main meal with "junk food" was found with $6 \%$ (regularly) and $40 \%$ (sometimes).

\section{Overweight}

In the medical history, $10 \%$ of the subjects questioned had a tendency to being overweight in childhood and conversely, $10 \%$ had a tendency to being emaciated. In the family history, excessive weight in the mother was found in $15 \%$ of the cases, in the father in $8 \%$ and in a brother or sister in $3 \%$ of the cases.

With $30 \%$ of the respondents, weight gain occurred in the past most often as a result of discontinuing sports, an illness, using birth control, and after marriage.

\section{Weight control}

If questioned whether the respondent would want to lose weight, $73 \%$ answered positively and $27 \%$ negatively. The main reasons for losing weight were general dissatisfaction with themselves in $26 \%$ of the cases and aesthetic reasons in $21 \%$. One half of the subjects questioned admitted using various methods to control their weight, mostly by regular exercise $(13 \%)$, fasting $(7 \%)$, or a combination of methods ( $19 \%)$. Only $1 \%$ reported the use of laxatives or diuretics.

In $50 \%$ of the families questioned dieting was the method reported to achieve slenderness. This was mostly the case for the mother (25\%), or the brother or sister (6\%). $70 \%$ of those questioned overalls were trying to lose weight, again by a combination of various methods (35\%), by exercising ( $21 \%$ ) or dieting (3\%). Weight loss on a short-term basis was reported by $27 \%$ of the respondents, on a long-term basis by $11 \%$ and on a permanent basis by $15 \%$. In $10 \%$ of the cases the effort to lose weight was unsuccessful.

\section{Significant signs of food intake disorder}

Vomiting after a meal was currently reported by $6 \%$ of those questioned, in the past by $5 \%, 89 \%$ had never had this problem. A closer analysis of the individual groups illustrates, that the use of vomiting after a meal as a means of regulating excessive food intake applied to the following groups: dancers, ballet dancers, and cosmetic school students.

Episodes of overeating, during which a person was losing control over their eating habits, was reported by $23 \%$ of the respondents $-13 \%$ of these at the present time and $5 \%$ in the past. The episodes of overeating occurred at 
about the same rate in all monitored groups with a higher frequency in the cosmetic school students, dancers, ballet dancers and figure skaters (overall incidence of almost $30 \%)$.

\section{Evaluation of the patient's data}

Between 1993 and 1994 at the psychiatric clinic of the medical faculty of the Palacky University, Olomouc, a total of 15 patients were hospitalized for food intake disorder. From 15 distributed questionnaires 8 were completed and returned. Only 5 of these contained data relevant to the patient's condition just prior to hospitalization. These five were further analyzed, at least from the point of view of the basic indicators.

The patients were age 11 to 19 and their average EAT questionnaire score was 55.2, (i.e., 3.5 times higher than the groups being studied). Their average BMI was 15.3 as compared to 19.9 in the groups being studied. The average weight was only $37.2 \mathrm{~kg}$ versus $56.4 \mathrm{~kg}$ in the groups being studied. The average height was $160.0 \mathrm{~cm}$ as compared to $168.3 \mathrm{~cm}$ in the groups being studied.

\section{DISCUSSION}

The main objective of this study is to assess the frequency of the condition which already shows signs of the beginning of a food intake disorder or which could result in this disorder.

With this in mind the respondents' data have been analyzed. The aim was to see if they partially met some of the diagnostic criteria for a food intake disorder as listed in the chapter "Mental and Behavioural Disorders", International Illness Classification, revision no. X, 1992.

All the criteria were assessed in all groups. Some selected questions were assessed only within individual groups in an effort to assess their higher or lower vulnerability to the food intake disorders.

\section{Evaluation of all groups together}

The basic evaluation was carried out using the EAT questionnaire assessment. It demonstrated that out of the total of 403 persons questioned, 47 had a score $>29$ points, which represents $11.7 \%$ of the persons questioned. These persons represent a potential risk population for the eventual development of this illness and the percentage of prevalence is consistent with the findings of other authors $^{3}$. The highest average score is naturally much lower than the score found in a small group of patients, where it was almost 3 times higher.

Forty-four persons in total, which represents $10.9 \%$ of the questioned, had the BMI lower or equal to 17.5 . This is another important segment at risk of the examined population. Out of these, only 5 individuals had the score $>29$ because, especially at potential or initial stages, these two parameters do not have to necessarily correspond. Therefore we are dealing with different respondents from those who had a positive EAT questionnaire and because of this, the percentage of potential risk population already rises to about $20 \%$. Also the average BMI was significantly lower for an individual group of patients in comparison with the all the examined groups together.

Further diagnostic parameters were found in the respondents' answers as follows:

- avoiding meals from which a person gains weight ... 100 persons $(24.7 \%$ ) answered positively

- vomiting after meal was rare but still there were 3 cases $(0.7 \%)$.

Induced vomiting after a meal because of overeating was reported more often, namely by 24 persons ( $6 \%$ ) currently and 21 persons $(5.2 \%)$ in the past. In case of two persons, the frequency of this was even several times a week. At the same time vomiting does not have to be present unconditionally. The food intake disorder also includes so-called impulse overeating, after which, unlike in the case of bulimic overeating, vomiting does not necessarily follow ${ }^{4}$ :

- use of laxatives was reported by 6 persons ( $1.4 \%$ )

- strenuous excessive exercise to burn calories was reported by 118 persons (29.2\%), exercise in the belief that calories are being burned was reported by 137 persons $(34.1 \%)$. Exercise to control weight was practised by 52 persons questioned $(12.9 \%)$ and exercise to lose weight was reported by $188(46.7 \%)$ persons currently and $109(27.0 \%)$ persons in the past

- psycho-pathology related to fear or fear from the excess weight was involved in $122(30.2 \%)$ respondents and attention to the shape of one's own body related to the dissatisfaction with some body parts in $322(79.9 \%)$ subjects questioned. These aspects are often one of the motivating factors to initiate a diet that can later result in a food intake disorder ${ }^{5,6}$

- psychopathology related to the need to have a low weight became apparent in response to the question whether the respondent has frequent thoughts of becoming slimmer. 212 (52.7\%) subjects gave a positive answer. Furthermore, 48 (11.9\%) subjects were on a diet with the purpose of becoming slimmer or to maintain their existing slenderness. In addition the fact, that 309 (76.8\%) subjects reported their ideal weight as being smaller than their current weight indicates a significant importance of this factor

- as far as the endocrine disorder is concerned it was not found to be related to amenorrhoea, however 113 (28.1\%) girls reported irregular menstruation and 23 subjects $(5.7 \%)$ currently and $38(9.4 \%)$ in the past reported an interruption of menstruation for a period of more than 3 months, which represents a relatively significant finding

- overeating episodes were reported by 95 (23.6\%) subjects questioned.

\section{Individual evaluation by groups}

The evaluation of the individual groups reflects only a trend since the groups were not completely homogeneous. In the groups representing students from individual fields of study other sports or profession categories could have been represented. In addition, the number of sub- 
jects in the individual groups was not the same since it depended on the availability of the categories in the questionnaire.

Even with this preliminary comparison, interesting differences were found, which could indicate potential changes of risk for the respective categories.

As far as the EAT questionnaire score is concerned, it made no difference whether we took the average score or a percentage of subjects with a positive score, the top gymnasts and figure skaters were the groups with the highest degree of risk. The top gymnasts and figure skaters were also found with the lowest BMI average.

The other selected factors such as vomiting, overeating, controlling weight by various methods and excessive fear or even fear of excess weight were represented at a higher percentage in the groups of the cosmetic school students as well as in all four categories with the sports or profession orientation (ballet dancers, models, figure skaters and gymnasts).

Overall we can conclude that the top gymnasts and figure skaters, followed by the models, dancers, ballet dancers and the cosmetic school students can be classified as having the highest degree of risk.

The high school students, faculty of medicine students and nursing college students appear to have the lowest degree of risk.

\section{CONCLUSIONS}

The main objective of a descriptive cross-sectional pilot study as this is to find out the incidence of the studied parameters, which could prove to be risk factors, related to a certain illness.
In this regard, the study has met the set goals, because the conclusion resulting from this study, confirmed the original assumption. In the population of young girls, primarily ones affiliated to certain sports or professional categories, many risk factors and risk behaviours can be identified that can result in some of the forms of food intake disorder.

These identified characteristics could form a hypothesis and could serve as a basis for further analytical and eventually intervention studies to try to prevent the development of food intake disorders in young girls.

\section{ACKNOWLEDGEMENTS}

This work was supported by the GA $\check{C} R$ no. 313/95/1418 grant.

\section{REFERENCES}

1. Devaud C, Michaud PA, Narring F. (1995) Anorexia and bulimia: increasing disorders? Rev Epid Sante Publique 43, 347-360.

2. Fombonne E. (1995) Anorexia nervosa. No evidence for increase. Br J Psych 166, 462-471.

3. Fairburn CG, Beglin SJ. (1990) Studies of the epidemiology of bulimia nervosa. Am J Psych 147, 401-408.

4. Krch FD, Málková I. SOS nadváha. Granit. 1993.

5. Cooper PJ. Bulimia Nervosa, A Guide to Recovery. Robinson Publishing London. 1993.

6. Herpetz S, Schweiger U. (2001) Psychobiologische Aspekte der Anorexia nervosa. Z Psychosom Med Psychother 47, 179-204. 